\title{
HUBUNGAN ANTARA TINGKAT PENGETAHUAN REMAJA PUTRI TENTANG DISMINORE DENGAN KESIAPAN MENGHADAPI DISMINORE DI RW 03 KELURAHAN KALIJATEN KECAMATAN TAMAN SIDOARJO TAHUN 2021
}

\author{
Ardiyanti Hidayah ${ }^{1}$, Najah Soraya Niah ${ }^{2}$ \\ ${ }^{1,2}$ STIKES Husada Jombang
}

\begin{abstract}
Introduction :Dysminore is painful during menstruation, usually with a sense of cramps and concentrated in the lower abdomen. This research aims to Analyze the relationship between the level of knowledge of young women about disminore with readiness to face disminore in the Kalijaten sub-district, Taman Kecamatan Sidoarjo regency. Methode: Observational Analytic Design, cross sectional approach of population 54 young adolescent girls early teens middle adolescents late teens, Simple Random Sampling sample technique, a sample of 48 teenage data collection by Questionnaire, coding data processing, scoring, tabulating and analyzed by chi square test. Result: Results of research on adolescent girls The majority of teenagers' knowledge is sufficient, namely 21 people (83.3\%), most of the girls who will face disminore who have preparedness are 37 people (77.1\%). Statistical testing with chi square test obtained $p$ value $\alpha \alpha$ with $p=0.000$. shows there is a relationship between the level of knowledge of young women with readiness to face disminore in Rw 03 Kalijaten Village Taman District Sidoarjo Regency. Discussion : From the results of the analysis it is expected for medical personnel to provide counseling and education for adolescents to be ready to face disminore and accept that disminore is something physiological to a woman.
\end{abstract}

Keywords: Knowledge Level, Disminore Readiness

\section{A. PENDAHULUAN}

Masa remaja merupakan merupakan masa perkembangan transisi antara masa anak dan masa dewasa yang mencakup perubahan biologis, kognitif dan sosial emosional (Zakiah Drajat 2012), pada masa ini remaja putri akan mengalami menstruasi dan tidak jarang disertai dengan disminore yaitu nyeri pada saat haid yang merupakan suatu gejala dan bukan suatu penyakit. Disminore atau nyeri yang dirasakan pada saat haid merupakan gangguan ginekologi yang sekarang ini sering terjadi di kalangan wanita yang menginjak masa remaja. Sekitar 30-75\% wanita mengalami dismenore (Ali, 2012). Disminore memberi dampak yang buruk pada remaja putri, sekitar $10 \%$ penderita disminore tidak dapat mengikuti kegiatan sehari-hari, aktifitas belajarnya di sekolah terganggu karena tidak dapat berkonsentrasi belajar sehingga motivasi belajar akan menurun dan tak jarang hal ini membuat remaja putri tidak masuk sekolah, selain itu disminore tidak hanya menyebabkan gangguan aktivitas tetapi juga memberi dampak bagi fisik, psikologis, sosial dan ekonomi terhadap seluruh wanita misalnya cepat letih, mual, muntah, nyeri kepala, sering marah, dan konsentrasi buruk (Bobak, 2012). Berdasarkan data World Health Organization pada tahun 2013 angka kejadian disminore di dunia cukup tinggi, rata-rata lebih dari 50\% perempuan di setiap negara mengalami disminore, sedangkan pada tahun 2014 angka kejadian disminore sebanyak 
55\%. Pengetahuan kesehatan reproduksi sebaiknya dilakukan sejak remaja, karena seseorang akan dapat mengenali kelainan pada kesehatan reproduksinya sedini mungkin, terutama tentang menstruasi (Kin Kusmiran (2012). Menurut World Health Organization tahun 2015 (WHO) usia remaja dimulai sejak usia 12-24 tahun. Remaja merupakan individu yang sedang mengalami masa peralihan yang secara berangsurangsur mencapai kematangan seksual, mengalami perubahan jiwa dari jiwa kanakkanak menjadi dewasa, dan mengalami perubahan keadaan ekonomi dari ketergantungan menjadi relatif mandiri (Notoatmodjo, 2012).

Angka kejadian disminore di Indonesia adalah sekitar $45-95 \%$ pada usia produktif, sedangkan angka kejadian disminore tipe primer sebesar 54,89\% (Depkes RI, 2014). Angka kejadian dismenore di Jawa Timur tahun 2013 sebesar 64,25\% yang terdiri dari 54,89\% disminore primer dan 9,36\% disminore sekunder (Dinkes Jawa Timur, 2013). Pusat Informasi dan Konseling Kesehatan Reproduksi Remaja (PIKKRR) pada tahun 2012 menunjukan angka kejadian disminore primer 72,89\% dan disminore sekunder $27,11 \%$ di Indonesia. Disminore primer $90 \%$ terjadi pada wanita yang telah mengalami menarche dan berlanjut hingga usia pertengahan 20-an atau hingga mereka memiliki anak (Irianto, 2015).

Berdasarkan hasil wawancara dengan remaja putri di wilayah RW 03 Kelurahan Kalijaten Kecamatan Taman yang dilakukan pada bulan Januari-Maret, sebanyak 10 remaja putri yang mengalami dismenore sampai tidak dapat melakukan aktifitas karena merasa nyeri, dimana terdiri dari 3 orang $(30 \%)$ remaja awal, $6(60 \%)$ remaja tengah dan $1(10 \%)$ remaja akhir, hal tersebut menunjukan bahwa penyebab tidak mengertinya remaja tentang kesiapan menghadapi disminore yaitu kurangnya pengetahuan remaja tentang disminore. Berdasarkan latar belakang diatas, peneliti tertarik untuk mengadakan penelitian untuk mengetahui“ Hubungan Antara Tingkat Pengetahuan Remaja Putri Tentang Disminore Dengan Kesiapan Menghadapi Disminore Di Kelurahan Kalijaten Kecamatan Taman Kabupaten Sidoarjo"

\section{B. TINJAUAN PUSTAKA}

Disminore adalah nyeri saat haid, biasanya dengan rasa kram dan terpusat di abdomen bawah. Disminore dapat dibagi menjadi dua kelompok yaitu disminore primer dan disminore sekunder. Disminore primer adalah nyeri haid tanpa ditemukan keadaan patologi pada panggul atau alat kandungan dan organ lainnya, sedangkan disminore sekunder adalah nyeri haid yang berhubungan dengan berbagai keadaan patologi di organ genitalia. Derajat disminore atau nyeri menstruasi ini dapat terjadi bervariasi mulai dari yang ringan sampai berat

(Manuaba, 2012). Nugroho dan Utama (2014) mengatakan disminore apabila tidak segera diatasi akan mempengaruhi fungsi mental dan fisik individu sehingga mendesak untuk segera mengambil tindakan terapi secara farmakologis atau nonfarmakologis. Kesiapan menghadapi disminore adalah keadaan yamg menunjukan bahwa seseorang siap untuk mencapai salah satu kematangan fsisk yaitu menstruasi yang keluar dari tempat khusus wanita sehingga menyebabkan disminore yang terjadi secara periodik pada waktu tertentu dan siklik (berulang ulang). Faktorfaktor yang mempengaruhi kesiapan menghadapi disminore adalah pengetahuan, sikap usia, sumber informasi dan dukungan sosial ibu ( Wawan, 2011). Pengetahuan remaja tentang disminore atau nyeri menstruasi dapat dipengaruhi oleh beberapa faktor seperti dari segi pendidikan, usia, pekerjaan, lingkungan, kultur (sosial, budaya, agama), 
pengalaman, dan informasi. ( Lestari, 2015). Tindakan farmakologis yang dapat dilakukan pada penanganan disminore biasanya menggunakan obat anti peradangan non-steroid yang tersedia dan dijual bebas dan bisa juga terapi hormonal dengan pengawasan dokter. Selain obat-obatan, rasa nyeri disminore bisa dikurangi dengan tindakan nonfarmakologis seperti kompres hangat didaerah perut, latihan aerobik seperti (berjalan kaki, bersepeda dan berenang), dan teknik relaksasi atau yoga. Teori lain menyebutkan disminore dapat juga di cegah dengan cara melakukan pola hidup sehat seperti sering berolah raga, diit seimbang atau mengkonsumsi makanan yang bergizi, dan istirahat yang cukup pada saat menstruasi (Proverawati dan misaroh, 2012). Disminore pada remaja putri dapat diatasi dengan memberikan konseling dan edukasi serta pengetahuan yang baik bahwa disminore bukan merupakan penyakit atau keadaan yang berbahaya dan dapat diatasi dengan tindakan sederhana seperti melakukan kompres hangat pada daerah abdomen, melakukan olahraga ringan seperti berjalan kaki, bersepeda atau berenang dan melakukan yoga, sehingga remaja dapat mengurangi keluhan nyeri haid tersebut dan tidak akan mengganggu kegiatan sehari-hari.

\section{METODE PENELITIAN}

Populasi : semua remaja putri diwilayah Kalijaten yang berjumlah 54 orang.

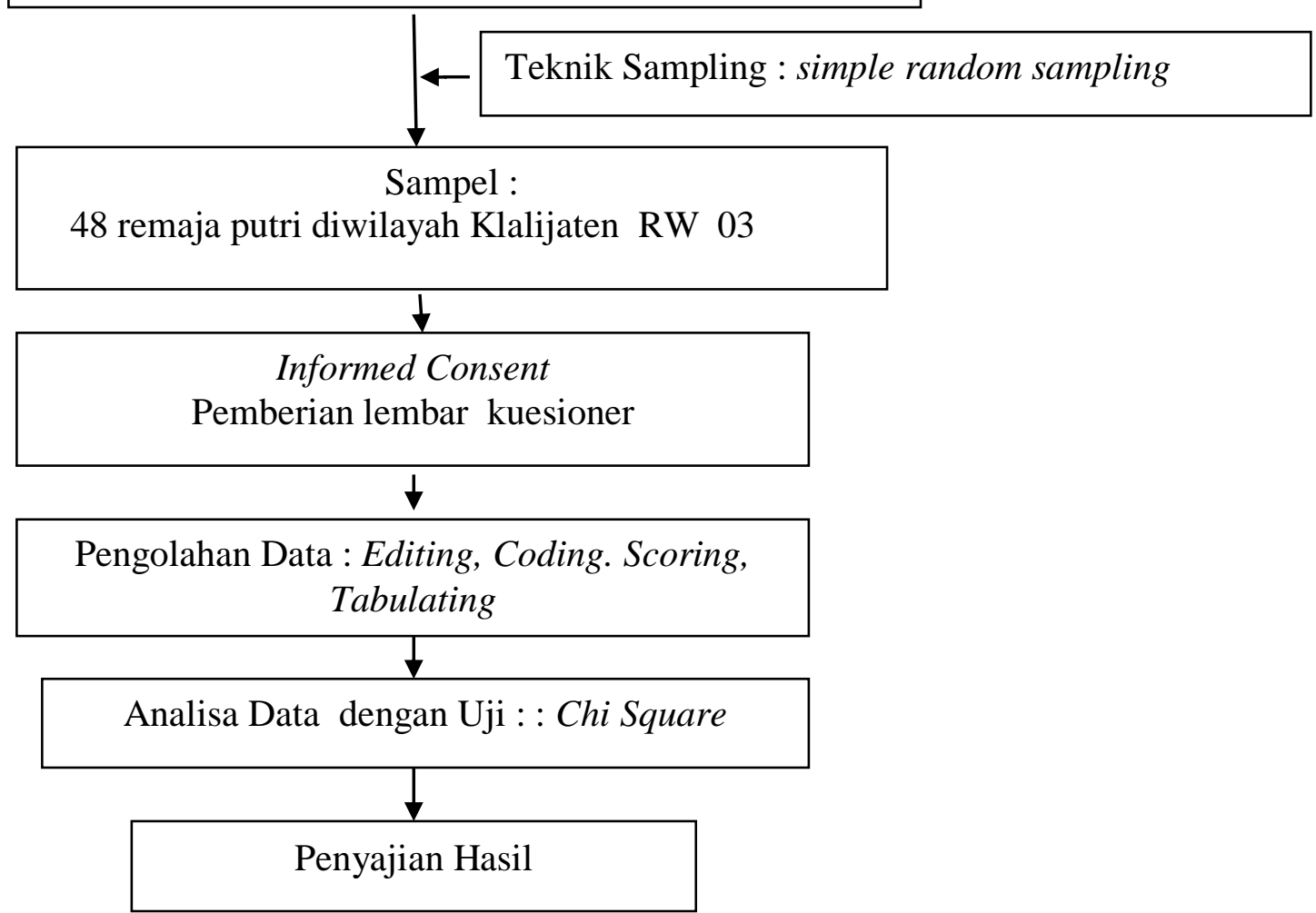

Gambar 4.1 Kerangka Operasional Hubungan Tingkat Pengetahuan Remaja PutriTentang Disminore Dengan Kesiapan Menghadapi Disminore di Rw 03 Kelurahan Kalijaten. 


\section{HASIL PENELITIAN}

Distribusi Frekuensi Tingkat Pengetahuan Remaja Putri Berdasarkan Umur di Rw 03 Kekurahan Kalijaten Kecamatan taman Kabupaten Sidoarjo Pada Bulan Mei - Juni 2021

\begin{tabular}{|c|c|c|c|}
\hline No & Usia & Frekuensi & Persentase \\
\hline 1. & $12-15$ & 18 & 37,5 \\
\hline 2. & $16-18$ & 17 & 35,41 \\
\hline 3. & $19-21$ & 13 & 27,09 \\
\hline \multicolumn{2}{|l|}{ Jumlah } & 48 & 100 \\
\hline
\end{tabular}

Menunjukan bahwa dari 48 remaja putri yang akan menghadapi disminore yang berumur 12-15 sebanyak 18 (37,5\%), remaja putri yang berumur 16-18 sebanyak 17 $(35,41 \%)$,remaja putri yang berumur $19-21$ sebanyak $13(27,09 \%)$. Dan diketahui dari 48 remaja putri sebagian besar remaja awal berumur $12-15(37,5 \%)$.

Distribusi Frekuensi Tingkat Remaja Putri Berdasarkan pendidikan di Rw 03 Kelurahan Kalijaten Kecamatan taman Kabupaten Sidoarjo Pada Bulan Mei Juni 2021

\begin{tabular}{|l|l|c|c|}
\hline No & \multicolumn{1}{|c|}{ Pendidikan } & Frekuensi & Persentase \\
\hline 1 & SD-SMP & 37 & 77,1 \\
\hline 2 & SMA & 11 & 22,9 \\
\hline 3 & Г/Akademik & 0 & 0 \\
\hline \multicolumn{2}{|c|}{ Jumlah } & 48 & 100 \\
\hline
\end{tabular}

Menunjukan bahwa dari 48 remaja putri yang akan menghadapi disminore berpendidikan SD-SMP sebanyak $37(77,1 \%)$ remaja putri yang berpendidikan SMA sebanyak 11 ( 22,9 ) remaja putri yang berpendidikan PT / Akademik sebanyak 0 $(0 \%)$. Diketahui dari 48 remaja putri sebagian besar berpendidikan SD-SMP Sebanyak $37(77,1 \%)$

Distribusi Frekuensi Tingkat Remaja Putri Berdasarkan pengetahuan di Rw 03 Kelurahan Kalijaten Kecamatan taman Kabupaten Sidoarjo Pada Bulan Mei Juni 2021

\begin{tabular}{|c|l|c|c|}
\hline No & \multicolumn{1}{|c|}{ Pengetahuan } & Frekuensi & Persentase \\
\hline 1 & Baik & 19 & 39,6 \\
\hline 2 & Cukup & 21 & 43,8 \\
\hline 3 & Kurang & 8 & 16,6 \\
\hline
\end{tabular}




\begin{tabular}{|c|c|c|}
\hline Jumlah & 48 & 100 \\
\hline
\end{tabular}

Menunjukan bahwa dari 48 remaja putri yang akan menghadapi disminore sebagian besar memiliki pengetahuan cukup sebanyak 21 orang $(43,8 \%)$, remaja putri yang berpengetahuan baik sebanyak $19(39,6 \%)$, remaja putri yang berpengetahuan kurang sebanyak $8(16,6 \%)$. Diketahui dari 48 remaja putri sebagian besar memiliki pengetahuan cukup sebanyak $21(83,3 \%)$.

Distribusi Frekuensi Remaja Putri Berdasarkan Kesiapan remaja Putri di Rw 03 Kelurahan Kalijaten Kecamatan taman Kabupaten Sidoarjo Pada Bulan Mei Juni 2021

\begin{tabular}{|l|l|c|c|}
\hline No & \multicolumn{1}{|c|}{ Kesiapan } & Frekuensi & Persentase \\
\hline 1 & Siap & 37 & 77,1 \\
\hline 2 & Tidak siap & 11 & 22,9 \\
\hline \multicolumn{2}{|l|}{ Jumlah } & 48 & 100 \\
\hline
\end{tabular}

Menunjukan bahwa dari 48 remaja putri yang akan menghadapi disminore sebagian besar yang memiliki kesiapan siap sebanyak 37 orang $(77,1 \%)$, remaja putri yang tidak memiliki kesiapan menghadapi disminore sebanyak $11(22,9 \%)$ diketahui dari 48 remaja putri sebagian besar memilili kesiapan siap sebanyak $37(77,1 \%)$.

Tabulasi silang pengetahuan remaja Putri dengan Kesiapan menghadapi disminore di Rw 03 Kelurahan Kalijaten Kecamatan taman Kabupaten Sidoarjo Pada Bulan Mei - Juni 2021

\begin{tabular}{|l|c|c|c|c|c|c|}
\hline \multirow{2}{*}{ Pengetahuan } & \multicolumn{4}{|c|}{ Kesiapan } & \multicolumn{3}{c|}{ Jumlah } \\
\cline { 2 - 6 } & \multicolumn{2}{|c|}{ Siap } & \multicolumn{2}{|c|}{ Tidak Siap } & \\
\cline { 2 - 7 } & F & $\%$ & F & $\%$ & 19 & 100 \\
\hline Baik & 17 & 89,5 & 2 & 10,5 & 21 & 100 \\
\hline Cukup & 2 & 9,5 & 19 & 90,5 & 8 & 100 \\
\hline Kurang & 1 & 12,5 & 7 & 87,5 & 48 & 100 \\
\hline Jumlah & 20 & 42 & 28 & 58 & & \\
\hline
\end{tabular}

Dari 48 remaja putri yang akan menghadapi disminore dengan kesiapan siap dan pengetahuan baik sebanyak 17 orang $(89,5 \%)$ lebih besar dibandingkan dengan pengetahuan cukup sebanyak 2 orang $(9,5 \%)$ dan pengetahuan kurang sebanyak 1 orang $(12,5 \%)$. Remaja putri yang akan menghadapi disminore dengan kesiapan tidak siap dan pengetahuan cukup sebanyak 19 orang $(90,5 \%)$ lebih besar dibandingkan dengan pengetahuan kurang sebanyak 7 orang $(87,5 \%)$ dan pengetahuan baik sebanyak 2 orang $(10,5 \%)$. 


\section{E. PEMBAHASAN}

Pengetahuan Hasil penelitian menunjukan bahwa terdapat hubungan antara tingkat pengetahuan remaja putri dengan kesiapan menghadapi disminore di Rw 03 kelurahan kalijaten kecamatan taman kabupaten sidoarjo. Sebanyak $21 \quad(83,3 \%)$ memiliki tingkat pengetahuan cukup dan kesiapan siap dan tidak siap disminore adanya hubungan antara kedua variabel ditunjukan dari hasil pengetahuan yang dimiliki maka semakin baik kesiapan yang dalam menghadapi disminore.

Berdasarkan hasil analisis dengan uji chi square untuk mengetahui hubungan antara tingkat pengetahuan remaja putri dengan kesiapan menghadapi disminore hasil uji statistik didapatkan nilai signifikan $\mathrm{p} \leq \alpha$ dengan $\mathrm{p}=0.000$ ini menunjukan bahwa H0 ditolak dan H1 diterima sehingga ada hubungan antara tingkat pengetahuan remaja putri dengan kesiapan menghadapi disminore.

Semakin baik pengetahuan tentang disminore yang dimiliki remaja putri maka kesiapan menghadapi disminore juga semakin baik. Dengan pengetahuan yang baik akan mempengaruhi kesiapanya siap dan tidak siap tergantung dari pemahaman dari individu remaja putri itu sendiri.

\section{F. PENUTUP}

Remaja putri sebagian besar berpengetahuan cukup sebanyak 21 (38,3\%). Remaja Putri sebagian besar mempunyai kesiapan siap menghadapi disminore sebanyak $37(77,1 \%)$. Berdasarkan Hasil analisis dengan uji chi square untuk menilai hubungan antara tingkat pengetahuan remaja putri dengan kesiapan menghadapi disminore Hasil uji statistik didapatkan nilai signifikan $\mathrm{p} \leq \alpha$ dengan $\mathrm{p}=0.000$ maka terdapat hubungan yang signifikan antara tingkat pengetahuan remaja putri dengan kesiapan menghadapi disminore

\section{G. DAFTAR PUSTAKA}

BKKBN. 2012. Reproduksi Sehat Sejahtera Remaja. Jakarta.

Dinkes Prov. Jatim. 2013. Profil kesehatan provinsi jawa timur 2013.

(online).www.depkes.go.id.

Irianto, K. 2015. Memahami Berbagai Macam Penyakit. Bandung: Alfabeta.

Lestari, Titik. 2015. Kumpulan Teori Untuk Kajian Pustaka Penelitian Kesehatan. Yogryakarta: Nuha Medika.

Manuaba. 2012. Memahami Kesehatan Reproduksi Wanita, Jakarta : Arcan.

Nugroho, T dan Utama I.B. 2014. Masalah Kesehatan Reproduksi Wanita. Yogyakarta: Nuha Medika.

Notoatmodjo. 2012. Metodologi Penelitian Kesehatan. Jakarta : Rineka Cipta. 